\title{
Creatine: a miserable life without it
}

\author{
Theo Wallimann ${ }^{1} \cdot$ Roger Harris ${ }^{2}$
}

Published online: 15 July 2016

(C) Springer-Verlag Wien 2016

$\begin{array}{ll}\text { Abbreviations } \\ \text { CK } & \text { Creatine kinase } \\ \text { Cr } & \text { Creatine } \\ \text { PCr } & \text { Phosphoryl creatine } \\ \text { TCr } & \text { Total Cr, Cr plus PCr } \\ \text { CrT } & \text { Creatine transporter or solute carrier SLC6A8 } \\ \text { GAA } & \text { Guanidinoacetic acid } \\ \text { P-GAA } & \text { Phosphoryl guanidinoacetic acid } \\ \text { GPA } & \text { Guanidinopropionic acid } \\ \text { AGAT } & \text { Arginine: glycine amidinotransferase } \\ \text { GAMT } & \text { Guanidinoacetate methyltransferase }\end{array}$

\section{"Creatine in Health, Sport and Medicine": an introduction to a Focus Group Meeting held in Laufen, Germany, in April 2015}

Following a memorable International Conference on "Creatine in Health, Medicine and Sport", held in July 2010 in the Howard Theatre, Downing College, Cambridge University, UK, organized by Roger Harris ${ }^{(*)}$ [see Special Issue in Amino Acids Vol. 40(5) May 2011], it was decided to continue the tradition by organizing a similar event 5 years later. As a result, a second FGM on "Creatine in Health, Sport and Medicine" was held between April 21st and 25th

Handling Editor: T. Wallimann and R. Harris.

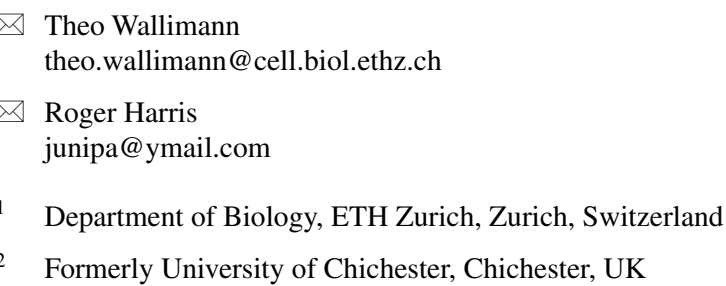

in the old monastery, now a conference center (Kapuzinerhof), in the small town of Laufen, Germany, located on the German/Austrian border. The meeting was organized by Theo Wallimann ${ }^{(\#)}$ and Roger Harris ${ }^{(*)}$.

The purpose of the Laufen meeting was again to bring together leading biochemists, molecular biologists, geneticists, physiologists and clinical researchers, with those directly involved in the translation of creatine research into practical applications for health, medicine and sport. Within the past decade, the creatine field has moved from being a topic of interest mainly for those involved in sport and strength training, to numerous aspects of human health and disease, where new, and in cases surprising, findings have continued to be made over the past five years (see this Special Issue: Creatine).

From a total of 80 international participants from all continents, 28 researchers presented invited lectures, and 3 out of a total of 29 posters were selected for short oral presentations. Twenty-five research groups now present their work here in this special issue of Amino Acids, either as reviews or as original work.

\section{General impressions and appraisal of progress in CK research}

The conference site at the old monastery in Laufen was superb, with restored monks cells, a professional conference infrastructure, and the delights of both an indoor and outdoor restaurant with excellent Bavarian food/beer and large monastery garden, fostering a climate of scientific exchange and open discussion on current research, and the joy and privilege of being a scientist, including problems with funding. A number of scientific contacts were reinforced and new collaborations begun, the results of which are likely to be presented at the next conference, planned 
for 2022. All in all, this was an ideal place to hold such a meeting. Thankfully, AlzChem AG in Trostberg, Germany, the only Western manufacturer of creatine monohydrate $\left(\right.$ Creapure $\left.^{\circledR}\right)$, sponsored all invited speakers, and the highly professional staff of the company, led by Dr. Barbara Niess, managed most of the administrative work. The organizers wish to thank all persons involved in this event for their excellent, highly motivated work.

\section{Basic science: old and new creatine kinase micro-compartments}

Skeletal muscle, due to its homogeneity (some $55 \%$ of total protein is myosin, $20 \%$ is actin, and $25 \%$ of proteins constitutes the rest), high specialization and high structural order, was the organ of choice for localization studies of $\mathrm{CK}$ and for the isolation and characterization of ATPaseassociated CK micro-compartments. Dimeric cytosolic muscle-type MM-CK is found associated with the contractile apparatus at the sarcomeric M-band, where it is functionally coupled to the myofibrillar actin-activated myosin ATPase, at the sarcoplasmic reticulum coupled to the $\mathrm{Ca}^{2+}$ pump ATPase), and at the sarcolemma, where it is coupled to the $\mathrm{Na}^{+} / \mathrm{K}^{+}$-ATPase. In addition, a mitochondrial $\mathrm{mtCK}$ isoform is localized between the inner (IM) and outer membrane $(\mathrm{OM})$ of mitochondria, where this octameric mtCK is sandwiched between the ATP carrier of the IM and the voltage-dependent anion carrier (VDAC) of the OM (for review see Wallimann et al. 1992, 2011).

Due to the abundance of these proteins and structures, it was relatively easy to isolate highly purified myofibrils, SR vesicles and plasma membrane preparations, as well as mitochondria, where CK localization was confirmed by various techniques employing light and electron microscopy and functional tests performed with highly enriched preparations. The isolation of such micro- compartments, however, becomes increasingly more difficult with the heterogeneity of other tissues, e.g. brain, where there is a multitude of highly different cell types that are not organized in a homogeneous, orderly fashion as with skeletal muscle (see Hanna-El-Daher and Braissant 2016).

Using sophisticated membrane and vesicle isolation procedures and yeast two-hybrid analysis suited to identify membrane proteins as interaction partners, Schlattner et al. (2016) identified a number of membrane proteins of the brain associated with brain-type cytosolic BB-CK. These novel micro-compartments of BB-CK with, for example, VAMP2 proteins and JWA, shed new light on synaptic functions dependent on BB-CK-mediated energy provision. Again using brain tissue, BB-CK was shown, after phosphorylation at serine residue number 6 by AMP-activated protein kinase (AMPK), to be targeted to endoplasmic reticulum membranes (ER) in propinquity to the $\mathrm{ER} \mathrm{Ca}^{2+}$
ATPase pump. This is the first example of phosphorylationdependent targeting of CK to a specific subcellular location demonstrating that, depending on the energy status of the brain cells, BB-CK may be directed to the SR where highly energy-dependent processes such as calcium pumping need optimal energy provision at the site of ATP demand. The coordinated action of the energy sensor AMPK with an important enzyme in energy metabolism, BB-CK, is a noteworthy event that may be a general feature in many other cells (Schlattner et al. 2016).

Yan (2016) presented new findings of his laboratory, demonstrating a distinct micro-compartment of BB-CK that is associated with the mitotic spindle apparatus, which needs high levels of energy for initiating and proceeding with cell division. BB-CK, found to be important for the energetics of cell division and cell cycle control, may thus also be involved in cancer cell progression and metastasis. Down-regulation or inhibition of CK by inhibitors or siRNA appears to retard mitosis, promote apoptosis and reduce metastasis, whereas creatine supplementation itself has now been convincingly shown to provide anti-cancer effects (Campos Ferraz et al. 2016; Deminice et al. 2016a; Pal et al. 2016).

\section{Creatine in health}

Consuming a normal balanced diet, including fresh meat and fish, modern man may receive sufficient amounts of the carninutrient creatine for optimal body functions. However, additional creatine supplementation may be indicated for athletes to achieve further improvement in performance. Creatine supplementation (3-4 g/day is shown not only to improve muscle mass and performance, both short term high-intensity and endurance, but also to improve recovery after heavy exercise and avoid muscle soreness and injury (see Roberts et al. 2016; Twycross Lewis et al. 2016).

In their review of the role of dietary creatine, Brosnan and Brosnan (2016) lead us through the evolutionary history of paleolithic (carnivore) to modern man (omnivore or vegetarian), looking at the ingested amounts of dietary creatine. Clearly, vegetarians, and even more so vegans, show lower plasma and muscle levels of total creatine than do omnivores. The authors reason that the gastrointestinal tract and the liver are exposed to higher concentrations of creatine before it is assimilated by the target tissues, skeletal and cardiac muscle, and brain and nervous tissue, and that this may be related to the very interesting finding that creatine is important, via enhanced cellular energetics of intestinal epithelial cells, in maintaining the intestinal barrier function under healthy condition, as well as in ameliorating mucosal inflammation in animals suffering from inflammatory bowel disease (Glover et al. 2013). In addition, the novel finding that the liver-which under normal 
conditions is the only organ in the body that is not expressing CK - can be prevented from developing into fatty liver or NAFL through creatine supplementation in animals fed a high-fat diet is rather unexpected. This would indicate that creatine not only serves cellular energy-related functions (enhanced PCr/ATP ratio), but also may be involved in hitherto unknown signaling pathways in lipid metabolism (Deminice et al. 2016b), thus supporting the pleiotropic effects of creatine (Wallimann et al. 2011).

In a comprehensive review, Gualano et al. (2016) discuss the potential benefits of creatine supplementation for the aging population and highlight the positive effects of creatine on skeletal muscle, especially if combined with training, as well as on bone and brain function. Future studies with older individuals, frail elderly and those with cognitive decline were proposed. In general, to support the encouraging data, larger human trials with longer duration of physical training and creatine supplementation are needed to definitely recommend creatine supplementation specifically for the management of age-related deficits such as sarcopenia (Pinto et al. 2016).

A review concerning differences in sex-specific responses to creatine supplementation and exercise between male and female human subjects was presented by Ellery et al. (2016a). The apparent endocrine modulation of creatine metabolism may be one explanation, but much work is still needed in this area; for example, future creatine supplementation studies should be conducted with cohorts of women followed through the menstrual cycle, as well as during pregnancy and then post-partum. Thus, gender-specific research with creatine is developing into a very interesting topic that deserves specific attention in the future [see also the publication by Kondo et al. (2016), who describe gender-specific positive effects of creatine for young women with severe depression].

This review is then followed by original work of the same group showing that maternal dietary creatine supplementation during pregnancy in a rodent animal model, the spiny mouse, protected the neonate from multi-organ damage, if birth was taking place under conditions with intrapartum hypoxia and birth asphyxia (Dickinson et al. 2014). Since the effects of nutritional supplementation during pregnancy must be subject to careful investigation, Ellery et al. (2016b) again used the spiny mouse model and fed mid-gestation pregnant and virgin spiny mice with a rather high dose of $5 \% \mathrm{w} / \mathrm{w}$ creatine in the chow for 18 days, followed by analysis of the expression pattern of the two enzymes involved in endogenous creatine synthesis, AGAT and GAMT, as well as of the creatine transporter $(\mathrm{CrT})$. From these data, it appeared that creatine supplementation had no effect on the body weight and composition, and only a minimal impact on endogenous creatine metabolism in either pregnant or non-pregnant spiny mice. However, increasing maternal dietary creatine ingestion during pregnancy was found to be useful for preventing birth asphyxia in the spiny mouse animal model (Ellery et al. 2016b). These data are supported by independent evidence showing that creatine fed to pregnant rats favors brain development and protects the embryonic and neonate brain in vivo against cellular stressors (Sestili et al. 2016). This should open the way for future clinical pilot studies with pregnant women to investigate whether maternal dietary creatine consumption through extra meat or fish or through direct creatine supplementation, preferentially during the last trimester of pregnancy, could also be useful for treating birth asphyxia in humans, as suggested by Wallimann et al. (2011).

In conclusion, it is generally accepted now that creatine is an essential metabolite for normal cell and body function, from embryonic life to adulthood, into senescence, for men and women, as well as for pregnant women and the newborn. A lack of creatine, as seen in creatine deficiency syndromes due to either genetic defects of the enzymes involved in endogenous creatine synthesis, AGAT or GAMT (Stockebrand et al. 2016; Schulze et al. 2016), or genetic defects in the creatine transporter (CrT) (Santacruz and Jacobs 2016; Perna et al. 2016), leads to more or less severe neuromuscular and neurological phenotypes, similar to what is seen in CK-deficient (Streijger et al. 2005) or creatine-depleted (GPA) animal models (Wyss and Wallimann 1994). Thus, a specific caveat should be announced here for women who consume vegan or vegetarian diets, and thus who have lower levels of total creatine in their body organs, to either switch their diet to allow for fresh meat and fish during pregnancy or to supplement with highly pure creatine in order to support healthy embryonic and neonatal development (see Wallimann et al. 2011).

\section{Creatine in sport}

A major incentive for studies on creatine was the 1992 report that the total creatine pool $(\mathrm{PCr}+\mathrm{Cr})$ in muscle could be increased in humans subjects within as little as 5 days when $20 \mathrm{~g}$ of creatine monohydrate per day was given as a dietary supplement (Harris et al. 1992), and the subsequent reporting in multiple studies that this resulted in an increase in high-intensity exercise performance (e.g. Greenhaff et al. 1993). As a result, creatine supplementation was adopted as a performance-enhancing supplement by athletes around the time of the 1992 Barcelona Olympics. However, for reasons unknown, the response to creatine supplementation was highly variable (Harris et al. 1992; Greenhaff et al. 1994), and our understanding of why this should be the case has advanced little in the past two decades. At the time of the initial studies, investigations 
were hampered by the need to take percutaneous muscle biopsies, and in most cases were limited to just one muscle, m. vastus lateralis. Janssen et al. (2016) report on the extraordinary advances being made with MRS, which could resolve this issue of variability. Using a clinical 3T MRS unit able to detect both ${ }^{1} \mathrm{H}$ and ${ }^{13} \mathrm{C}$ spin resonances, coupled with supplementation with ${ }^{13} \mathrm{C}$-enriched creatine, the authors were able to estimate in vivo $\mathrm{Cr}$ uptake, turnover and $\mathrm{PCr} / \mathrm{TCr}$ ratios of individual muscles (biceps femoris, semimembranosus, semitendinosus, adductor magnus and gracilis) in an examination taking just $1 \mathrm{~h}$. Although described as a feasibility study, indications of variability in the response to $\mathrm{Cr}$ supplementation between muscles within the same individual and due to age and gender are also reported. The failure of some individuals to respond to creatine supplementation has been an issue in many studies, particularly where effects on exercise performance were being investigated but where no actual measurements of muscle $\mathrm{TCr}$ were included, as well as a cause of disappointment to individual athletes themselves. As much as anything else, the study by Janssen et al. (2016, in this issue) highlights the amazing technological advances made since the aforementioned muscle biopsy study of 1992 and others on the level of $\mathrm{Cr}$ and $\mathrm{PCr}$ in human muscle at rest and in response to exercise (Harris et al. 1974; Hultman et al. 1967).

Ostojic (2016) reviews the possible use of guanidinoacetic acid (GAA) to increase creatine in muscle and as an ergogenic aid. The kidney and pancreas are assumed to be the principal organs for GAA synthesis through the action of AGAT, and is itself the immediate precursor of $\mathrm{Cr}$. The final methylation step to $\mathrm{Cr}$ is performed by GAMT and was assumed (with the exception of brain) to occur primarily in the liver, although other sites including muscle (Daly 1985) have been suggested based on GAMT localization. In papers reviewed by Ostojic (2016), oral administration of GAA was effective in raising the muscle $\mathrm{TCr}$ pool, which because of its greater stability in aqueous and mildly acidic conditions makes it an attractive alternative to $\mathrm{Cr}$ in sport-related products. This would clearly be the case if GAA were equally or more effective than orally supplied creatine in raising the muscle TCr pool. However, as reviewed by Ostojic in this issue regarding the pharmacovigilance of GAA, concerns remain over the safety of regular supplementation with GAA, not least because of the elevation of plasma homocysteine, which has been recognized as a risk factor for cardiovascular and arteriosclerotic disease. As noted in the article, this raises the question of whether GAA supplementation could ever be considered for use by athletes as an ergogenic aid, even if it proved to be more effective than $\mathrm{Cr}$ in raising the muscle $\mathrm{TCr}$ pool, and despite its greater amenity for inclusion in sports products.
A detailed review of the ergogenic benefits to athletes of creatine elevation in muscle is presented in Twycross Lewis et al. (2016). Based initially on studies of Harris et al. (1992), supplementation with $20 \mathrm{~g}$ per day of creatine monohydrate for 5-10 days was advocated, achieving a 25-30\% increase in muscle $\mathrm{TCr}$, that was then followed by a maintenance dose of $3 \mathrm{~g}$ per day. However, about $30 \%$ of individuals, principally those with $\mathrm{TCr}$ content close to $150 \mathrm{mmol} / \mathrm{kg}$ dry muscle, showed little or no increase (non-responders), whereas those with initial content of less than $110 \mathrm{mmol} / \mathrm{kg} \mathrm{dm}$ showed the greatest increase (Harris et al. 1992; Greenhaff et al. 1994). Alternative supplementation programs achieving the same increase in muscle $\mathrm{TCr}$ involve considerably lower doses, though for much longer periods (Hultman et al. 1996). Still unresolved, however, is the primary mechanism by which $\mathrm{TCr}$, and specifically $\mathrm{PCr}$, exerts an ergogenic effect. Is this through the provision of additional "high-energy phosphate" for ATP re-synthesis, or through the maintenance of low intracellular ADP concentrations? The possibility that it is the latter is supported by the lower exercise-related plasma hypoxanthine and uric acid concentrations (markers of adenine nucleotide degradation) following $\mathrm{Cr}$ supplementation (Tang et al. 2014) and the lower post-exercise muscle IMP concentration (McConell et al. 2005). In this alternative model, the primary role of $\mathrm{PCr}$ in exercising muscle is in preventing the accumulation of ADP triggering the onset of adenine nucleotide degradation via myokinase/AMP deaminase to IMP, and subsequently to hypoxanthine, a role which fits with the relative properties of the $\mathrm{PCr}-\mathrm{CK}$ system compared with other members of the phosphorylguanidino family (Ellington 1989). Twycross Lewis et al. (2016) raise the additional possibility that the increase in water retention in muscle with $\mathrm{Cr}$ supplementation, possibly associated with increased muscle glycogen storage (Fernández-Elías et al. 2015), may help in the maintenance of total body hydration and fatigue resistance when exercising under hot ambient conditions likely to contribute to dehydration and thermal stress. This, together with the documented ergogenic effects of muscle creatine elevation, would be important to athletes performing in endurance events, especially in hot climates, as well as to military personnel operating in desert conditions.

Although Cr supplementation has been demonstrated in previous studies to enhance muscle glycogen recovery following glycogen-depleting exercise, Roberts et al. (2016) describe for the first time the time course over which this occurs. While, once again, $\mathrm{Cr}$ supplementation augmented muscle glycogen recovery, it was evident that this occurred not as a gradual bifurcation from the typical glycogen-loading response expressed in the placebo group, but as a transient, almost twofold increase in the resynthesis rate during the initial $24 \mathrm{~h}$. Furthermore, the authors concluded from 
previous work (Robinson et al. 1999) that the enhancement of glycogen synthesis by $\mathrm{Cr}$ must have occurred between 6 and 24 h post exercise. The authors were unable to suggest a mechanism to explain this intriguing and unexpected finding. For many athletes and sports persons where events are held on adjacent days, such as professional tennis, where inclement weather disrupts the normal programme, the advantage to be gained by enhanced glycogen recovery in such a short period may be the difference between focused and unfocused play in the following tournament round. Intriguingly, in this study, glycogen recovery from an almost depleted state in both the placebo and Cr-supplemented subjects was not associated with any increase in muscle water, which would seem to contradict the findings of Fernández-Elías et al. (2015) cited above.

\section{Creatine in developing muscle and brain, cell- and neuroprotection and clinical studies}

Creatine metabolism has long been thought to be a relatively simple process involving two enzymatic steps and a creatine transporter, with endogenous synthesis of creatine taking place first in the kidney (via AGAT to give GAA) and then in the liver (via GAMT to give creatine), from where it is exported into the blood system and transported to the target cells and organs, mainly skeletal and cardiac muscle and the brain and neuronal tissue, via a creatine transporter (LSC6A8 or CrT). Alimentary creatine acquired via creatine transporters of the small intestine would take the same route once reaching the bloodstream, from where it would be taken up by the target organs, including the brain. However, it now turns out that peripherally supplied creatine has only limited permeability to the brain, as the creatine transporter is absent from the astrocytes that surround brain blood vessels at the blood-brain barrier. The laboratory of Olivier Braissant convincingly demonstrated that the brain possesses the potential for endogenous creatine synthesis, contrary to what has been believed for decades. In addition, there is a complicated heterogenic mosaic-like expression of creatine kinase (CK) isoenzymes, the two creatine synthesis enzymes (AGAT and GAMT) and the creatine transporter (CrT) in different cells throughout the brain. Due to this complexity, there is intracellular exchange of GAA and/or creatine between the different brain cells, which, similar to neurotransmitter trafficking between brain cells, complicates the picture (Hanna-El-Daher and Braissant 2016). Creatine is not only the precursor of the high-energy $\mathrm{PCr}$ that, together with micro-compartmentalized CK isoenzymes, is important for brain energetics (Wallimann et al. 2011), but can also function as a neurotransmitter. In their comprehensive and beautifully illustrated review, the authors explain in a unifying theory how their findings relate to the different clinical phenotypes of the three creatine deficiency syndromes and also explain why GAA can be toxic to the brain (Hanna-ElDaher and Braissant 2016).

Creatine promotes a wide range of physiological responses that go beyond its contribution in satisfying cellular energy needs. The laboratory of Sestili et al. (2016) has convincingly shown that creatine promotes in vitro muscle cell and neuron differentiation and displays muscle cell and neuroprotective effects, both in vitro and in vivo, e.g. against oxidative stress. For example, creatine accelerates the differentiation process from myoblasts into myotubes. Creatine also favors the electrophysiological maturation of neuroblasts in vitro and protects both muscle and neuronal cells from oxidative stress. Interestingly, maternal Cr supplementation has also been shown to promote the morpho-functional development of hippocampal neurons in rat offspring in vivo, thus providing a rationale for creatine supplementation during pregnancy to support brain development, maturation and protection against cellular stressors in the embryonic and neonate brain (Sestili et al. 2016).

As transplanted neuronal progenitor or stem cells may have a therapeutic clinical potential in the future, but are often difficult to cultivate and to bring to differentiation, cell cultures were used to study the trophic and cell-protective effects of creatine (see above) in early (E14) and late (E18) developmental stages of rat striatal progenitor cells (Andres et al. 2016). Similar to earlier experiments, the findings corroborated evidence that creatine is indeed a GABA-ergic differentiation factor, but additionally demonstrated that this effect is dependent on the developmental stage of the progenitor neurons, in that creatine significantly increased the number of branching points in the E18-stage but not in the E14-stage progenitor cells. These data, which are also supported by the results of Sestili et al. (2016) showing that creatine improved the differentiation and electrophysiological maturation of neuroblasts in vitro, may have implications for selection of the optimal developmental stage of cells to be grafted into the brain for therapeutic purposes.

Because creatine, a natural nutritional supplement, has shown astonishing neuroprotection in experimental animals as model systems for neurodegenerative diseases such as ALS and Parkinson's and Huntington's disease (for review, see Beal 2011), it seemed logical that clinical researchers around the world would first undertake pilot and then large-scale clinical trials with creatine at various dosages, mostly in patients showing full-fledged symptoms. Andreas Bender and Thomas Klopstock, who pioneered this work in Munich, analyzed the outcomes of all of the clinical trials, and concluded that creatine supplementation at variable dosages (usually 5-10 g, but also up to $30 \mathrm{~g}$ per day for many months) in several controlled multi-center clinical trials involving over 1000 patients showed no benefit 
in any of these neurodegenerative diseases (Bender and Klopstock 2016). Whether the neuroprotective effects of creatine could display a preventive effect if administered to the patients before the actual insult, accompanied by the onset of the pathophysiological cascade, remains a topic for future clinical trials. What certainly emerged from the study is that creatine supplementation is safe, even if given to patients at relatively high doses for a prolonged period of time-for example, in one RCT study, 1687 patients or healthy controls received a daily average dose of $9.5 \mathrm{~g}$ of creatine for a total of 5480 patient-years, with no significant side effects registered (see Tables 1-3 in Bender and Klopstock 2016).

As a part of the National Institute of Mental Health's experimental medicine initiative, Kondo et al. (2016), in a careful clinical study, investigated the effect of creatine supplementation ( 2.4 or $10 \mathrm{~g}$ per day, for 8 weeks) in adolescent girls with antidepressant-resistant major depressive disorder (MDD)who did not respond to serotonin reuptake inhibitors. MDD is likely related to brain mitochondrial dysfunction, and is predicted to become the leading cause of global disease burden by 2030 . Using ${ }^{31} \mathrm{P}-\mathrm{NMR}$ spectroscopy, the authors demonstrated a dose-dependent increase in phosphocreatine $(\mathrm{PCr})$ in the frontal lobes of subjects treated with creatine and, most importantly, showed a clear inverse correlation between brain PCr content and depression scores (Kondo et al. 2016). In light of the disappointing results obtained in human patients with ALS and Parkinson's and Huntington's disease (see Bender and Klopstock, above), these data for patients suffering from treatment-resistant MDD are significant and very encouraging. But the reason that females and not males with MDD respond to creatine treatment remains an enigma, although it may be related to those genderspecific effects of creatine also reported by Ellery et al. (2016a). However, the fact that simple substitution with creatine monohydrate might serve as an efficient adjuvant therapeutic intervention in females suffering from MDD is rather exciting and deserves further, larger-scale clinical studies.

\section{Creatine in heart function and liver pathology}

It is widely accepted that creatine is of the utmost importance for cellular energetics in skeletal and cardiac muscle as well as in brain and neuronal tissues. Unfortunately, in clinical studies, creatine supplementation has shown no significant positive effects in chronic neurodegenerative diseases (see above). Balestrino et al. (2016) surmise that creatine may be better suited for clinical interventions in more acute situations, where tissues undergo an energy deficit crisis, e.g. during ischemic stroke in the brain or myocardial ischemic attack leading to heart infarction. However, since creatine would have to be energetically charged to PCr before it could develop its potential, and because the tissue in question is itself energy-depleted and thus cannot use its ATP to charge PCr, creatine should then be administered preventively to patients at high risk of stroke, even before the event takes place. An alternative approach, proposed and researched successfully by the group around Valdur Saks already in the 1980s (Ruda et al. 1988) and followed up by Balestrino et al. (2016), is that PCr is directly administered to patients by intravenous infusion as early as possible after an ischemic heart attack and during cardiac surgery. This strategy resulted in a significant improvement in cardiac parameters and subsequent prevention of cardiac arrhythmia, which is often also a problem after cardiac surgery. However, despite a convincing rationale with experimental clinical evidence for the addition of $\mathrm{PCr}$ to cardioplegic solutions, this promising intervention has not yet been widely adopted by cardiac intervention and surgery clinics. It seems that larger multi-center studies are needed so that $\mathrm{PCr}$ - which, due to its inherent chemical instability in aqueous solution, would have to be dissolved as freeze-dried powder directly into the cardioplegic solution just before use-can be brought to fruition for the benefit of patients with cerebral and cardiac ischemic attacks (Balestrino et al. 2016).

In their earlier provocative work entitled "Living without creatine", Lygate et al. (2013) showed that transgenic mice without GAMT voluntarily ran as fast and performed the same level of work when tested to exhaustion on a treadmill, and additionally, that their survival following myocardial infarction was not altered in comparison to wild-type animals. Based on these results, the authors questioned the long-held paradigm that creatine is essential for high workload and chronic stress responses in heart and skeletal muscle. However, in addition to the fact that these GAMT knockout mice show severely altered guanidino compound levels, lower body weight and impaired fertility (Schmidt et al. 2004), they accumulate significant amounts of guanidinoacetate (GAA), which is phosphorylated by $\mathrm{CK}$ to form energy-rich P-GAA, as seen clearly by ${ }^{31} \mathrm{P}-\mathrm{NMR}$ spectroscopy in vivo in skeletal and cardiac muscle (Heerschap et al. 2007). It is well known that P-GAA can still serve, albeit less efficiently than $\mathrm{PCr}$, as a substrate for the CK reaction to replenish ATP from P-GAA (Boehm et al. 1996). Although Lygate et al. (2013), using ${ }^{31}$ P-NMR saturation transfer measurements, were apparently unable to show a phosphoryl-transfer from the energy-rich P-GAA to ADP to give ATP in cardiac muscle, this had been shown earlier to take place in vivo, at least in skeletal muscle (Kan et al. 2004). There is no apparent explanation as to why this would not also happen in cardiac muscle, where a clearly discernible P-GAA peak was visible. Since the flux through the CK system is orders of magnitude higher than the 
highest ATP turnover reaction, only a relatively small flux through the CK reaction, in this case from P-GAA to ATP, would be needed to satisfy cardiac energy needs (Wallimann 1996). Perhaps this phosphoryl transfer flux was too low to be measured by the method employed? Since the accumulated P-GAA levels are generally high in GAMT knockout animals, it is likely that the relatively mild phenotype in terms of skeletal and cardiac muscle performance can be explained by this fact. Thus, the results described above do not justify the conclusions taken by Lygate et al. (2013), specifically in light of the fact that reduced PCr concentrations and PCr/ATP ratios, as well as a reduced flux through the CK reaction, have been consistently seen in human myocardial infarction (Bottomley et al. 2009).

Zervou et al. (2016) show in an elegant study that mice over-expressing the creatine transporter $(\mathrm{CrT})$, and thus displaying elevated cardiac total creatine levels, were protected against ischemia/reperfusion injury via improved energy reserves. However, mice with very high cardiac creatine concentrations developed more or less severe cardiac hypertrophy and dysfunction. Using these latter mice for an integrated proteomic and metabolomics study, the authors found that mice with very high cardiac creatine content showed reduced expression of multiple proteins. In a parallel metabolomics analysis using ${ }^{1} \mathrm{H}-\mathrm{NMR}$ spectroscopy, significant changes in a number of key metabolites were also detected that implied impairment of glycolysis, fatty acid oxidation and the TCA cycle, resulting in a substraterich but energy-poor heart. These results revealed hitherto unsuspected feedback mechanisms between creatine content and many key metabolites in the heart (Zervou et al. 2016) that argue for a pleiotropic action of creatine, in addition to those effects already known (Wallimann et al. 2011). Such sophisticated combined proteomic and metabolomics approaches are likely to add yet another dimension to the fields of CK and creatine research, as also exemplified by Stockebrand et al. (2016).

Fatty liver is the early stage of nonalcoholic fatty liver disease (NAFLD), which can lead to nonalcoholic steatohepatitis (NASH) and eventually to hepatocellular carcinoma. The incidence of these diseases is rising globally. However, there is no specific treatment for them. In a comprehensive review, Demenice et al. (2016b) summarized the literature on the subject and also presented data of their own showing that creatine supplementation prevented liver fat accumulation in rats with either 3 weeks of a high-fat diet or 4 weeks of a choline-deficient diet. Total liver fat and liver triglycerides, as well as liver TBARS as an indicator of oxidative insult, were significantly lower in rats fed a high-fat diet supplemented with creatine than in controls. This project certainly seems ripe for clinical studies with humans to test whether creatine is a new therapeutic approach to treating fatty liver disease.

\section{Creatine and cancer}

Creatine and creatine analogues such as cyclo-creatine have long been known to inhibit tumor growth in vitro and experimentally in animals (Miller et al. 1993). Now, an exploratory study looking at potential mechanisms corroborates these findings and demonstrates unambiguously that creatine supplementation is indeed able to significantly slow tumor growth, by approximately $30 \%$, in tumorbearing rats. Ultimately, however, creatine treatment did not improve overall survival of the experimental animals. At the same time, inflammatory parameters associated with cachexia as well as metabolic acidosis in tumor-bearing rats were lowered by creatine (Campos Ferraz et al. 2016). In addition, inflammatory parameters including TNF-a, C-reactive protein and IL-6, as well as markers for oxidative damage, were all lowered. The fact that creatine supplementation restored the impaired creatine-CK system in tumor cells led the authors to surmise that inhibition of AGAT and/or GAMT, which is thought to support cancer cell metabolism by contributing to polyamine and methionine synthesis, as shown by Locasale (2013), may be one of the reasons for the anti-cancer effects of creatine. The data reported by Campos Ferraz et al. (2016) are in accord with similar data by Patra et al. (2008), and suggest a potential therapeutic effect of creatine for the treatment of cancer (Pal et al. 2016). The latter authors present evidence that creatine supplementation should be viewed as an adjuvant therapeutic intervention together with methylglyoxal (MG), a long-known anti-cancer agent. The same authors demonstrate that the anti-cancer effect of MG is enhanced by concomitant creatine supplementation, both in chemically transformed muscle cells in vitro and in a sarcoma 180 animal model in vivo. Combination treatment with MG and creatine in tumor-bearing mice resulted in a marked reduction in tumor growth and a significantly better animal survival rate; this seemed to be especially true when ascorbic acid was included as the third compound in this mixture (Pal et al. 2016).

Another publication in this issue showed that creatine supplementation in Walker 256 tumor-bearing rats that developed cachexia, in parallel with higher oxidative stress and elevated plasma homocysteine (Hcy) levels, also resulted in an approximately $30 \%$ reduction in tumor growth. In addition, creatine treatment led to a reduction in plasma Hcy concentrations and hepatic oxidative stress in the tumor-bearing animals (Deminice et al. 2016a). Thus, again, the anti-cancer and anti-cachexia effects observed in this experimental animal cancer model simply by supplementation of creatine-which is an efficient and safe nutritional supplement also for humans-will justify further work along these lines, eventually testing creatine supplementation in clinical cancer trials. 
Animal models and human patients with creatine deficiencies: a miserable life without creatine

\section{AGAT deficiency}

Stockebrand et al. (2016) present novel and unexpected findings on the metabolic function of the $\mathrm{CK} / \mathrm{PCr}$ system, different from that of its known function for cellular energy buffering and intracellular energy shuttling (Wallimann et al. 2011). The transgenic mouse lacking AGAT, the enzyme for the first step of endogenous creatine synthesis, is a true creatine-deficient mutant, provided that this animal is not receiving any alimentary creatine that can be adsorbed via the creatine transporter (CrT) by the intestine. This is in contrast to the GAMT knockout counterpart (Zervou et al. 2016), which is able to synthesize guanidinoacetate (GAA). This GAA may then be phosphorylated to produce energy-rich P-GAA, which in turn can be used as a substrate by CK instead of PCr (Heerschap et al. 2007). In contrast to the latter, mice with AGAT deficiency present with complete absence of creatine and GAA in all tissues of the body and, as would be expected, with a severe muscle phenotype associated with reduced muscle strength, muscle atrophy, decreased ATP and increased inorganic phosphate (Pi) levels (Nabuurs et al. 2013). The latter situation results in significantly disturbed oxidative phosphorylation. In addition, the lack of metabolic interaction of the $\mathrm{PC} / \mathrm{Cr}$ system with AMP-activated protein kinase (AMPK) (Neumann et al. 2003) and the lowered energy state, as visualized by lowered ATP concentrations, in these transgenic AGAT knockout mice result in chronic activation of the AMPK, suggesting that the $\mathrm{PCr} / \mathrm{Cr}$ pool must also play a central role in whole-body energy homeostasis.

Searching for an explanation in this direction, Stockebrand et al. (2016) used a combined transcriptomic and metabolic analysis and found metabolic alterations in pyruvate conversion to alanine in the glucose pathway, as well as in enzymes of serine production and one-carbon metabolism, indicating that the $\mathrm{PCr} / \mathrm{Cr}$ system is not only an energy buffer and shuttle (Wallimann et al. 1992, 2011), but a crucial component involved in numerous systemic metabolic processes as well. This opens the field to the discovery of new avenues of metabolic physiology and signaling of $\mathrm{CK}$ and creatine. It is to be expected that the application of even faster and more sensitive omics technologies to the $\mathrm{CK} /$ creatine system will provide many unexpected novel insights into the metabolic network involving creatine.

\section{GAMT deficiency}

A deficiency of the enzyme for the second step of endogenous creatine synthesis, GAMT, leads to creatine depletion, but at the same time also to GAA accumulation in the brain.
The latter is a known to exert neurotoxic and epileptogenic seizures by inhibiting, among others, the $\mathrm{Na}^{+} / \mathrm{K}^{+}$-ATPase and CK activity, and is therefore responsible for the severe epileptic seizures seen in humans afflicted with this type of creatine deficiency syndrome. One strategy for lowering the GAA concentration in GAMT deficiency is to supplement with ornithine, the byproduct of AGAT, and thus to suppress the AGAT reaction through feedback inhibition. Here, Schulze et al. (2016) used transgenic GAMT-mutant mice to study brain activity and $\mathrm{GABA}_{\mathrm{A}}$-mediated mechanisms. Since GAA is also known to evoke picrotoxin-mediated chloride currents, the authors found that when they injected picrotoxin into the brain, wild-type mice reacted with induced seizures, but at the same dose of picrotoxin, GAMT-mutant mice did not develop such seizures. When GAMT-deficient mice and patients were treated with ornithine to reduce the concentration of accumulated GAA, their seizure phenotypes improved. Here, ornithine supplementation in GAMT-mutant mice before picrotoxin administration raised the seizure threshold, whereas the same mice treated simultaneously with both ornithine and picrotoxin no longer showed seizures. These data are important in that they contribute to a better understanding of the pathophysiology of seizures in human GAMT deficiency, where a $\mathrm{GABA}_{\mathrm{A}}$-mediated transmission takes place. Thus, together with an arginine-restricted diet and ornithine plus creatine supplementation, which constitutes the current standard treatment for GAMT-deficient patients, this very intervention when combined with picrotoxin may provide a rational basis for a therapeutic intervention in the future.

\section{Creatine transporter $(\mathrm{CrT})$ and $\mathrm{CrT}$ deficiency}

Under normal conditions, myocytes and neurons have only a limited capacity to endogenously synthesize their own creatine, which is needed, however, for proper physiological function. Therefore, such cells express a specialized creatine transporter (CrT), which belongs to the family of solute carriers SLC6A8. CrT is a two-sodium and onechloride creatine co-transporter that can be inhibited rather specifically by the creatine analogue guanidinopropionic acid (GPA). In their concise review, Santacruz and Jacobs (2016) present the facts known about CrT and provide some additional hints for possible regulatory mechanisms of $\mathrm{CrT}$ on the transcriptional and translational level by various signaling cascades and respective protein kinases and phosphatases, as well as by post-translational modification. In this respect, AMP-activated protein kinase (AMPK), which senses the cellular energy state by the intracellular PCr/ATP ratio, seems especially interesting. In cardiomyocytes, activation of AMPK activates creatine transport activity, likely to ensure sufficient provision of cardiac cells with the energy precursor creatine (Darrabie et al. 2011). 
In proximal kidney tubules, however, activation of AMPK inhibits creatine transporter activity, by down-regulation of the transport and/or insertion of the CrT protein into the apical membrane ( $\mathrm{Li}$ et al. 2010). This down-regulation of creatine transport could be important for reducing cellular energy expenditure for creatine reabsorption by the proximal tubules. Together with absorbed sodium, which would increase the energetic load on the $\mathrm{Na}^{+} / \mathrm{K}^{+}$-ATPase, this would be unfavorable under conditions of local and whole-body metabolic stress ( $\mathrm{Li}$ et al. 2010). Curiously, it is still not known whether AMPK, in fact, interacts directly with and phosphorylates CrT, or whether these effects are indirect via another protein kinase in the signaling cascade. Translational modification by $N$-linked glycosylation positively affects the insertion of CrT into the plasma membrane (Straumann et al. 2006). In light of the still rather fragmentary knowledge about $\mathrm{CrT}$, and the clinical importance of this transporter in this most severe form creatine deficiency syndrome, further and extensive studies on the structure, function and regulation of CrT would be of paramount importance for determining whether there still may be ways to channel creatine or usable analogues (by $\mathrm{CK}$ ) into cells genetically deficient in CrT (Kurosawa et al. 2012; Trotier-Faurion et al. 2015).

To elucidate the physiological importance of creatine in both a cellular and whole-animal context, Perna et al. (2016) describe some details of the phenotype of the first transgenic CrT knockout mouse as a high-fidelity animal model for human CrT deficiency. Phenotypically, these animals present with a reduced body mass, but at the same time with a twofold increase in body fat. Increased energy expenditure during treadmill running was observed in the CrT knockout mice compared to the wild type. Also, the cellular expenditure was higher in the CrT versus control mice. Finally, mitochondrial respiration was higher in the skeletal muscle and brain of CrT knockout mice compared to in controls. This, together with other data, indicated a higher mitochondrial content in the brain and skeletal muscles of the CrT knockout mice, similar to the situation seen in creatine-depleted (by GPA supplementation) or double-CK knockout mice (Wallimann et al. 1998). In these latter two cases, a generally lowered cellular energy state, caused either by reducing the availability of creatine as substrate for CK (by GPA supplementation) or by ablating the CK enzyme system as a whole, both resulted in a compensatory overproduction of mitochondria (Wiesner et al. 1999; O'Gorman et al. 1998). In the case of the CrT knockout mouse, one would expect to see similar changes in terms of mitochondrial propensity, size and shape, as well as in the appearance of intra-mitochondrial inclusions (O'Gorman et al. 1997). However, since CrT knockout mice still express in certain brain cells both creatine synthesis enzymes (AGAT and GAMT), as well as both brain-type CK isoenzymes, only those neurons will be affected, which are devoid of endogenous creatine synthesis and therefore depend on creatine import via an intact CrT (see Hanna-El-Daher and Braissant 2016). Thus, one would expect to see the above-mentioned mitochondrial changes only in a this subpopulation of neurons. Such an analysis may not be trivial, and this was likely why no pictures of such brain slices stained for mitochondria could be shown yet by Perna et al. (2016). It is hoped that a fullfledged, detailed analysis of the content and disposition of mitochondria in the different cells of the brain and in other tissues of CrT-deficient mice, including mitochondrial morphometry, will verify this hypothesis in the future. The data of Perna et al. (2016) with the CrT-knockout mice, however, show that without the CK-PCr-Cr system at work, the efficiency of energy utilization at the wholebody and cellular levels is lowered significantly, e.g. more oxygen and ATP are spent for the same amount of work in the CrT-deficient mice compared with wild-type animals (Perna et al. 2016). And this corresponds exactly to the theoretically predicted main physiological function of the entire CK-PCr-Cr system-that, by the CK-PCr-Cr system, the free energy change of ATP hydrolysis exemplified by $\left(\Delta G_{\text {ATP hydrolysis }}=\Delta G_{\text {obs }^{*}}-\mathrm{RT} \times \ln \left([\mathrm{ATP}] /[\mathrm{ADP}] \times\left[P_{\mathrm{i}}\right]\right)\right.$, which strongly depends on the ATP/ADP ratio, is kept high in resting as well as in working cells as long as possible, and this also during a high workload (Wallimann et al. 1992). This is facilitated by keeping the local ATP/ ADP ratio high at subcellular sites near cellular ATPases via associated cytosolic MM-CK; this is especially important, for example, in the vicinity of the energetically highly demanding $\mathrm{Ca}^{2+}$-ATPase or calcium pump at the sarcoplasmic reticulum (SR), or in conjunction with the sarcolemma $\mathrm{Na}^{+} / \mathrm{K}^{+}$-ATPase, where fractions of cytosolic MM-CK are co-localized (Wallimann et al. 2011). Supporting such an explanation is the most striking phenotype of the doubleCK knockout mouse, which presents with significant difficulty with muscle relaxation (Steeghs et al. 1997; Abraham et al. 2002), or conversely, by keeping the ADP/ATP ratio high in the vicinity of the mitochondrial ADP/ATP-carrier (ANT) in a tight functional micro-compartment with mitochondrial mtCK (Wallimann et al. 2011).

Again, obviously, the CrT knockout phenotype is not lethal, but its efficiency of energy utilization is severely impaired, even though this may be mitigated by compensatory metabolic changes, as for example also seen in the AGAT and GAMT knockout mice (see Stockebrand et al. 2016; Zervou et al. 2016), as well as in the CK knockouts (for review see Wallimann et al. 2011). It is to be expected that in the near future, a "true creatine knockout mouse" will be generated. Such an experimental model would have to be a double-knockout mouse with a combination of both CrT and AGAT deletions. This mutant should be unable to 
acquire alimentary creatine and to endogenously synthesis its own creatine, and finally, would be unable to transport creatine between various cells.

To conclude, creatine and its energy-charged form, phosphocreatine ( $\mathrm{PCr}$ ), in conjunction with the corresponding evolutionarily highly conserved enzyme creatine kinase (CK) (for review see Ellington and Suzuki 2007), all are essential for normal physiological body function and thus for a normal life. This is apparent from the various creatine-deficient animal models as well as their human counterparts. Although creatine deficiency is not instantaneously lethal, animals affected may not survive for any length of time in the wild, and human subjects suffering any of the creatine deficiency syndromes, be it AGAT, GAMT or CrT deficiency, are all more or less severely handicapped-for example, with significant mental retardation, needing permanent assistance in specialized institutions (for review of human creatine deficiency syndromes, see Schulze 2013). The generation of a "true creatine knockout transgenic animal model", which would be devoid of both CrT and AGAT, is of paramount importance, and will once and forever show the real phenotype, if not lethal, of creatine deficiency per se (see above).

So, then, living without creatine (Lygate et al. 2013) is not an option. Who would want to live with severe muscular atrophy, neuromuscular and neurological impairments, developmental speech delay, epileptic seizures, autism and brain atrophy, shivering due to lack of thermoregulation, as well as troubled fertility and reproduction, auditory hearing and sense of equilibrium, and many more? Patients with AGAT deficiency can be cured permanently by simple creatine supplementation, if the genetic defect is discovered early in life. Curing patients with GAMT deficiency is somewhat more difficult, since one must reduce endogenous synthesis and accumulation of GAA, which in these patients shows toxicity to the brain (see Schulze et al. 2016). Finally, if we could understand more of the basics of the CrT, that is, its function and regulation (see Santacruz and Jacobs 2016), we might also be able to bring creatine into those brain cells that are lacking the capacity of endogenous creatine synthesis and thus need an intact $\mathrm{CrT}$ in order to acquire creatine from the serum, as with muscle, or from surrounding astrocytes in the brain (see Hanna-ElDaher and Braissant 2016).

Some progress appears to have been made in this area using a mouse model with a genetic defect in the CrT, in that a creatine analogue, cyclo-creatine, can be transported into the brains of these animals, where it is phosphorylated to P-cyclo-creatine, which is still a reasonable substrate for the CK reaction and suited well enough for fulfilling the cellular energy needs (Kurosawa et al. 2012). It will be interesting to learn how this strategy will work for CrT-deficient human patients, for whom no cure at all exists for the consequences of the gene defect of CrT.

\section{Compliance with ethical standards}

Conflict of interest Both authors, TW and RH, declare no conflict of interest.

\section{References}

Abraham MR, Selivanov VA, Hodgson DM, Pucar D, Zingman LV, Wieringa B, Dzeja PP, Alekseev AE, Terzic A (2002) Coupling of cell energetics with membrane metabolic sensing. Integrative signaling through creatine kinase phosphotransfer disrupted by M-CK gene knock-out. J Biol Chem 277(27):24427-24434

Andres RA, Ducray AD, Andereggen L, Hohl T, Schlattner U, Wallimann T, Widmer HR (2016) The effects of creatine supplementation on striatal neural progenitor cells depend on developmental stage. Amino Acids. doi:10.1007/s00726-016-2238-8

Balestrino M, Sarocchi M, Enrico Adriano E, Spallarossa P (2016) Potential of creatine or phosphocreatine supplementation in cerebrovascular disease and in ischemic heart disease. Amino Acids. doi:10.1007/s00726-016-2173-8

Beal MF (2011) Neuroprotective effects of creatine. Amino Acids 40(5):1305-1313

Bender A, Klopstock T (2016) Creatine for neuroprotection in neurodegenerative disease: end of story?. Amino Acids 1-12. doi:10.1007/s00726-015-2165-0

Boehm EA, Radda GK, Tomlin H, Clark JF (1996) The utilization of creatine and its analogues by cytosolic and mitochondrial creatine kinase. Biochim Biophys Acta 1274(3):119-128

Bottomley PA, Wu KC, Gerstenblith G, Schulman SP, Steinberg A, Weiss RG (2009) Reduced myocardial creatine kinase flux in human myocardial infarction: an in vivo phosphorus magnetic resonance spectroscopy study. Circulation 119:1918-1924

Brosnan ME, Brosnan JT (2016) The role of dietary creatine. Amino Acids. doi:10.1007/s00726-016-2188-1

Campos Ferraz PL, Gualano B, das Neves W. Andrade IT, I. Hangai I, Pereira RTS, Bezerra RN, Deminice R, Seelaender M, Lancha AH (2016) Exploratory studies of the potential anti-cancer effects of creatine. Amino Acids 1-9. doi:10.1007/ s00726-016-2180-9

Daly MM (1985) Guanidinoacetate methyltransferase activity in tissues and cultured cells. Ach Biochem Biophy 236:576-584

Darrabie MD, Arciniegas AJ, Mishra R, Bowles DE, Jacobs DO, Santacruz L (2011) AMPK and substrate availability regulate creatine transport in cultured cardiomyocytes. Am J Physiol Endocrinol Metab 300:E870-E876

Deminice R, Cella PS, Padilha CS, Borges FH, Costa Mendes da Silva LE, Campos-Ferraz PL, Jordao AA, Robinson JL, Bertolo RF, Cecchini R, Guarnier FA (2016a) Creatine supplementation prevents hyperhomocysteinemia, oxidative stress and cancerinduced cachexia progression in Walker-256 tumor-bearing rats. Amino Acids 1-10. doi:10.1007/s00726-016-2172-9

Demenice R, de Castro GS, Brosnan ME, Brosnan JT (2016b) Creatine supplementation as a possible new therapeutic approach for fatty liver disease: early findings. Amino Acids 1-9. doi:10.1007/ s00726-016-2183-6

Dickinson H, Ellery S, Ireland Z, Larosa D, Snow R, Walker DW (2014) Creatine supplementation during pregnancy: summary of experimental studies suggesting a treatment to improve fetal 
and neonatal morbidity and reduce mortality in high-risk human pregnancy. BMC Pregn Childbirth 14:150

Ellery SJ, Walker DW, Dickinson H (2016a) Creatine for women: a review of the relationship between creatine and the reproductive cycle and female-specific benefits of creatine therapy. Amino Acids 1-11. doi:10.1007/s00726-016-2199-y

Ellery SJ, LaRosa DA, Kett MM, Della Gatta PA, Snow RJ, Walker DW, Dickinson H (2016b) Dietary creatine supplementation during pregnancy: a study on the effects of creatine supplementation on creatine homeostasis and renal excretory function in spiny mice. Amino Acids. doi:10.1007/s00726-015-2150-7

Ellington WR (1989) Phosphocreatine represents a thermodynamic and functional improvement over other muscle phosphagens. J Exp Biol 143:177-194

Ellington WR, Suzuki T (2007) Early evolution of the creatine kinase gene family and the capacity for creatine biosynthesis and membrane transport. Subcell Biochem 46:17-26

Fernández-Elías VE, Ortega JF, Nelson RK, Mora-Rodriguez R (2015) Relationship between muscle water and glycogen recovery after prolonged exercise in the heat in humans. Eur J Appl Physiol 115(9):1919-1926

Glover LE, Bowers BE, Saeedi B, Ehrentraut SF, Campbell EL, Bayless AJ, Dobrinskikh E, Kendrick AA, Kelly CJ, Burgess A, Miller L, Kominsky DJ, Jedlicka P, Colgan SP (2013) Control of creatine metabolism by HIF is an endogenous mechanism of barrier regulation in colitis. Proc Natl Acad Sci USA 110:19820-19825

Greenhaff PL, Casey A, Short AH, Harris R, Söderlund K, Hultman E (1993) Influence of oral creatine supplementation of muscle torque during repeated bouts of maximal voluntary exercise in man. Clin Sci 84:567-571

Greenhaff PL, Bodin K, Soderlund K, Hultman E (1994) Effect of oral creatine supplementation on skeletal muscle phosphocreatine resynthesis. The American journal of physiology $266(5 \mathrm{Pt}$ 1):E725-E730

Gualano B, Rawson ES, Candow DG, Chilibeck PD (2016) Creatine supplementation in the aging population: effects on skeletal muscle, bone and brain. Amino Acids. doi:10.1007/ s00726-016-2239-7

Hanna-El-Daher L, Braissant O (2016) Creatine synthesis and exchange between brain cells: what can be learned from human creatine deficiencies and various experimental models? Amino Acids. doi:10.1007/s00726-016-2189-0

Harris RC, Hultman E, Nordesjö LO (1974) Glycogen, glycolytic intermediates and high energy phosphates determined in biopsy samples of musculus femoris of man at rest. Methods in variance values. Scand J Clin Lab Invest 33:109-120

Harris RC, Soderlund K, Hultman E (1992) Elevation of creatine in resting and exercised muscle of normal subjects by creatine supplementation. Clin Sci 83(3):367-374

Heerschap A, Kan HE, Nabuurs CIHC, Renema WK, Isbrandt D, Wieringa D (2007) In vivo magnetic resonance spectroscopy of transgenic mice with altered expression of guanidinoacetate methyltransferase and creatine kinase isoenzymes. In: Salomons GS, Wyss M (eds) Creatine and Creatine Kinase in Health and Disease", Subcellular Biochemistry, vol 46. Springer, Dordrecht, pp 119-148

Hultman E, Bergström J, Anderson NM (1967) Breakdown and resynthesis of phosphorylcreatine and adenosine triphosphate in connection with muscular work in man. Scand J Clin Lab Invest 19(1):56-66

Hultman E, Soderlund K, Timmons JA, Cederblad G, Greenhaff PL (1996) Muscle creatine loading in men. J Appl Physiol 81(1):232-237

Janssen BH, Lassche S, Hopman MT, Wevers RA, Engelen BGM, Heerschap A (2016) Monitoring creatine and phosphocreatine by $13 \mathrm{C}$ MR spectroscopic imaging during and after $13 \mathrm{C} 4$ creatine loading: a feasibility study. Amino Acids. doi:10.1007/ s00726-016-2294-0

Kan HE, Renema WK, Isbrandt D, Heerschap A (2004) Phosphorylated guanidinoacetate partly compensates for the lack of phosphocreatine in skeletal muscle of mice lacking guanidinoacetate methyltranferase. J Physiol 560(1):219-229

Kondo DG, Forrest LN, Shi X, Sung YH, Hellem TL, Huber RS, Renshaw PF (2016) Creatine target engagement with brain bioenergetics: a dose-ranging phosphorus-31 magnetic resonance spectroscopy study of adolescent females with SSRI-resistant depression. Amino Acids. doi:10.1007/s00726-016-2194-3

Kurosawa Y, Degrauw TJ, Lindquist DM, Blanco VM, PyneGeithman GJ, Daikoku T, Chambers JB, Benoit SC, Clark JF (2012) Cyclocreatine treatment improves cognition in mice with creatine transporter deficiency. J Clin Invest. 122(8):2837-2846

Li H, Thali RF, Smolak C, Gong F, Alzamora R, Wallimann T, Scholz R, Pastor-Soler NM, Neumann D, Hallows KR (2010) Regulation of the creatine transporter by AMP-ACTIVATED protein kinase in kidney epithelial cells. Am J Physiol Renal Physiol 299:F167-F177

Locasale JW (2013) Serine, glycine and one-carbon units: cancer metabolism in full circle. Nat Rev Cancer 13:572-583

Lygate CA, Aksentijevic D, Dawson D, ten Hove M, Phillips D, de Bono JP, Medway DJ, Sebag-Montefiore LM, Hunyor I, Channon K, Clarke K, Zervou S, Watkins H, Balaban R, Neubauer S (2013) Living without creatine: unchanged exercise capacity and response to chronic myocardial infarction in creatine deficient mice. Circ Res 112(6):945-955

McConell GK, Shinewell J, Stephens TJ, Stathis CG, Canny BJ, Snow RJ (2005) Creatine supplementation reduces muscle inosine monophosphate during endurance exercise in humans. Med Sci Sports Exerc 37(12):2054-2061

Miller EE, Evans AE, Cohn M (1993) Inhibition of rate of tumor growth by creatine and cyclocreatine. Proc Natl Acad Sci U S A. 90(8):3304-3308

Nabuurs CI, Choe CU, Veltien A, Kan HE, van Loon LJ, Rodenburg RJ, Matschke J, Wieringa B, Kemp GJ, Isbrandt D, Heerschap A (2013) Disturbed energy metabolism and muscular dystrophy caused by pure creatine deficiency are reversible by creatine intake. J Physiol 591:571-592

Neumann D, Schlattner U, Wallimann T (2003) A molecular approach to the concerted action of kinases involved in energy homoeostasis. Biochem Soc Trans 31:169-174

O’Gorman E, Piendl T, Müller M, Brdiczka D, Wallimann T (1997) Mitochondrial intermembrane inclusion bodies: the common denominator between human mitochondrial myopathies and creatine depletion, due to impairment of cellular energetics. Mol Cell Biochem 174:283-289

O’Gorman E, Piendl T, Müller M, Brdiczka D, Wallimann T (1998) Mitochondrial intermembrane inclusion bodies: the common denominator between human mitochondrial myopathies and creatine depletion, due to impairment of cellular energetics. Mol Cell Biochem 174:283-289

Ostojic SM (2016) Guanidinoacetic acid as a performance-enhancing agent. Amino Acids. doi:10.1007/s00726-015-2106-y

Pal A, Roy A, Ray M (2016) Creatine supplementation with methylglyoxal: a potent therapy for cancer in experimental models. Amino Acids. doi:10.1007/s00726-016-2224-1

Patra S, Bera S, Sinha Roy S, Ghoshal S, Ray S, Basu A, Schlattner U, Wallimann T, Ray M (2008) Progressive decrease of phosphor creatine, creatine and creatine kinase in skeletal muscle upon transformation to sarcoma. FEBS J 275:3236-3247

Perna MK, Kokenge AN, Miles KN, Udobi KC, Clark JF, PyneGeithman GJ, Khuchua Z, Skelton MR (2016) Creatine 
transporter deficiency leads to increased whole-body and cellular metabolism. Amino Acids. doi:10.1007/s00726-016-2291-3

Pinto CL, Botelho PB, Carneiro JA, Mota JF (2016) Impact of creatine supplementation in combination with resistance training on lean bass in the elderly. J. Cachexia, Sarcopenia and Muscle 2016 Jan 18. doi:10.1002/jcsm. 12094 (Epub ahead of print)

Roberts PA, Fox J, Peirce N, Jones SW, Casey A, Greenhaff PL (2016) Creatine ingestion augments dietary carbohydrate mediated muscle glycogen supercompensation during the initial $24 \mathrm{~h}$ of recovery following prolonged exhaustive exercise in humans. Amino Acids 1-12. doi:10.1007/s00726-016-2252-x

Robinson TM, Sewell DA, Hultman E, Greenhaff PL (1999) Role of submaximal exercise in promoting creatine and glycogen accumulation in human skeletal muscle. J Appl Physiol 87:598-604

Ruda MY, Samarenko MB, Afonskaya NI, Saks VA (1988) Reduction of ventricular arrhythmias by phosphocreatine (Neoton) in patients with acute myocardial infarction. Am Heart J 116:393-397

Santacruz L, Jacobs DO (2016) Structural correlates of the creatine transporter function regulation: the undiscovered country. Amino Acids. doi:10.1007/s00726-016-2206-3

Schlattner U, Klaus A, Rios SR, Guzun R, Kay L, Tokarska-Schlattner M (2016) Cellular compartmentation of energy metabolism: creatine kinase microcompartments and recruitment of B-type creatine kinase to specific subcellular sites. Amino Acids 1-24. doi:10.1007/s00726-016-2267-3

Schmidt A, Marescu B, Ea Boehm, Renema WK, Peco R, Das A, Steinfeld R, Chan S, Wallis J, Davidoff M, Ulrich K, Waldschütz R, Heerschap A, De Deyn PP, Neubauer S, Isbrandt D (2004) Severely altered guanidino compound levels, disturbed body weight homeostasis and impaired fertility in a mouse model of guanidinoacetate N-methyltransferase (GAMT) deficiency. Human Mol Genet 13(9):905-921

Schulze A (2013) Creatine deficiency syndromes. Handb Clin Neurol 113:1837-1843

Schulze A, Tran C, Levandovskiy V, Patel V, Cortez MA (2016) Systemic availability of guanidinoacetate affects $\mathrm{GABA}_{\mathrm{A}}$ receptor function and seizure threshold in GAMT deficient mice. Amino Acids. doi:10.1007/s00726-016-2197-0

Sestili P, Ambrogini P, Barbieri E, Sartin S, Fimognari C, Calcabrini C, Diaz AR, Guescini M, Polidori E, Luchetti F, Canonico B, Lattanzi D, Cuppini R, Papa S, Stocchi V (2016) New insights into the trophic and cytoprotective effects of creatine in in vitro and in vivo models of cell maturation. Amino Acids 1-15. doi:10.1007/s00726-015-2161-4

Steeghs K, Benders A, Oerlemans F, deHaan A, Heerschap A, Ruitenbeck W, van Deursen JC, Perryman B, Pette D, Brückwilder M, Koudijs J, Jap P, Veerkamp J, Wieringa B (1997) Altered calcium responses in muscles with combined mitochondrial and cytosolic creatine kinase deficiencies. Cell 89:93-103

Stockebrand M, Nejad AS, Neu A, Kharbanda KK, Sauter K, Schillemeit S, Dirk Isbrandt D, Choe C (2016) Transcriptomic and metabolic analyses reveal salvage pathways in creatine-deficient $\mathrm{AGAT}^{-/-}$ mice. Amino Acids 1-15. doi:10.1007/s00726-016-2202-7

Straumann N, Wind A, Leuenberger T, Wallimann T (2006) Effects of N-linked glycosylation on the creatine transporter. Biochem J 393:459-469

Streijger F, Oerlemans F, Ellenbroek BA, Jost CR, Wieringa B, Van der Zee CE (2005) Structural and behavioural consequences of double deficiency for creatine kinase BCK and UbCKmt. Behav Brain Res 157(2):219-234

Tang FC, Chan CC, Kuo PL (2014) Contribution of creatine to protein homeostasis in athletes after endurance and sprint running. Eur J Nutr 53(1):61-71

Trotier-Faurion A, Passirani C, Béjaud J, Dézard S, Valayannopoulos V, Taran F, de Lonlay P, Benoit JP, Mabondzo A (2015) Nanomedicine (Lond.) 10:185-191

Twycross Lewis R, Kilduff LP, Wang G, Pitsiladis YP (2016) The effects of creatine supplementation on thermoregulation and physical (cognitive) performance: a review and future prospects. Amino Acids 1-13. doi:10.1007/s00726-016-2237-9

Wallimann T, Wyss M, Brdiczka D, Nicolay K, Eppenberger HM (1992) Intracellular compartmentation, structure and function of creatine kinase isozymes in tissues with high and fluctuating energy demands: the "phosphocreatine circuit" for cellular energy homeostasis. Biochem J 281:21-40

Wallimann $\mathrm{T}$ (1996) ${ }^{31} \mathrm{P}-\mathrm{NMR}$-measured creatine kinase reaction flux in muscle: a caveat!. J Muscle Res and Cell Motil 17(2):177-181. doi:10.1007/BF00124240

Wallimann T, Dolder M, Schlattner U, Eder M, Hornemann T, O'Gorman E, Rück A, Brdiczka D (1998) Some new aspects of creatine kinase $(\mathrm{CK})$ : compartmentation, structure, function and regulation for cellular and mitochondrial bioenergetics and physiology. BioFactors 8:220-234

Wallimann T, Tokarska-Schlattner M, Schlattner U (2011) The creatine kinase system and pleiotropic effects of creatine. Amino Acids 40:1271-1296

Wiesner RJ, Hornung TV, Garman JD, Clayton DA, O'Gorman E, Wallimann T (1999) Stimulation of mitochondrial gene expression and proliferation of mitochondria following impairment of cellular energy transfer by inhibition of the phosphocreatine circuit in rat hearts. J Bioenerg Biomembr 31:559-567

Wyss M, Wallimann T (1994) Creatine metabolism and the consequences of creatine depletion in muscle. Mol Cell Biochem 133-134:51-66

Yan YB (2016) Creatine kinase in cell cycle regulation and cancer. Amino Acids 1-10. doi:10.1007/s00726-016-2217-0

Zervou S, Yin X, Nabeebaccus AA, O'Brien BA, Cross RL, McAndrew DJ, Atkinson RA, Eykyn TR, Mayr M, Neubauer S, Lygate CA (2016) Proteomic and metabolomic changes driven by elevating myocardial creatine suggest novel metabolic feedback mechanisms Amino Acids. doi:10.1007/s00726-016-2236-x 